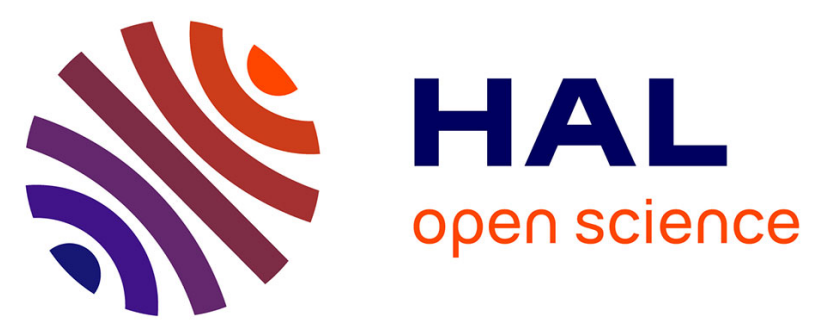

\title{
3D Compact High-Q Filter Made of High-Permittivity Ceramic
}

\author{
Yaakoub Dia, Laure Huitema, Stéphane Bila, Marc Thevenot, Nicolas \\ Delhote, Christophe Delaveaud
}

\section{- To cite this version:}

Yaakoub Dia, Laure Huitema, Stéphane Bila, Marc Thevenot, Nicolas Delhote, et al.. 3D Compact High-Q Filter Made of High-Permittivity Ceramic. European Microwave Conference, Sep 2019, Paris, France. 10.23919/EuMC.2019.8910921 . hal-02377005

\section{HAL Id: hal-02377005 \\ https://hal-unilim.archives-ouvertes.fr/hal-02377005}

Submitted on 8 Dec 2020

HAL is a multi-disciplinary open access archive for the deposit and dissemination of scientific research documents, whether they are published or not. The documents may come from teaching and research institutions in France or abroad, or from public or private research centers.
L'archive ouverte pluridisciplinaire HAL, est destinée au dépôt et à la diffusion de documents scientifiques de niveau recherche, publiés ou non, émanant des établissements d'enseignement et de recherche français ou étrangers, des laboratoires publics ou privés. 


\title{
3D Compact High-Q Filter Made of High- Permittivity Ceramic
}

\author{
Y. Dia ${ }^{\# *}$, L. Huitema ${ }^{\# 1}$, S. Bila ${ }^{\# 2}$, M. Thevenot ${ }^{\# 3}$, N. Delhote ${ }^{\# 4}$, C. Delaveaud ${ }^{* \times 5}$ \\ (\#) Université de Limoges, CNRS, XLIM UMR7252, Limoges, FRANCE \\ ${ }^{(*)}$ CEA LETI, Grenoble, FRANCE \\ (x) Université de Grenoble-Alpes, Grenoble, FRANCE \\ \{1 laure.huitema, ${ }^{2}$ stephane.bila, ${ }^{3}$ marc.thevenot, ${ }^{4}$ nicolas.delhote\}@xlim.fr, ${ }^{5}$ christophe.delaveaud@cea.fr
}

\begin{abstract}
This paper presents the design of a compact and high-Q microwave filter integrated by using a low-loss highpermittivity ceramic material. Further miniaturization is achieved by insertion of a capacitive post placed in the middle of each resonator. An unloaded quality factor of 385 is obtained for a miniaturized filter having typical dimensions of $\lambda_{0} / 7.5 \times \lambda_{0} / 7.5 \times$ $\lambda_{0} / 30$ at $2.5 \mathrm{GHz}, \lambda_{0}$ being the free space operating wavelength.

Keywords - ceramics, microwave filter, filter synthesis.
\end{abstract}

\section{INTRODUCTION}

The development of wireless communication devices leads to an increasing demand for miniaturization and integration of microwave circuits and subsystems. Since filters and duplexers often occupy a significant part of the device, the challenge consists in proposing new technological solutions bringing simultaneously a high unloaded quality factor for high performance (low insertion loss, low noise ...) and a reduced mass and footprint at competitive cost.

The classical approach uses planar technologies with, for instance, folded resonators [1]-[5] but, even with low-loss materials, such technologies are limited in terms of quality factor. Bulk acoustic-wave (BAW) filters [6], [7] allow bringing very small size and fairly good quality factors but the technology remains very expensive. On the other hand, empty or loaded cavity filters are attractive for high quality factors but their size and weight generally disqualify them.

Substrate integrated waveguides (SIW), fabricated using multilayer or 3D technologies [8]-[10], represent an alternative solution, allowing an interesting compromise between miniaturisation and performance. In this case, the compromise is essentially driven by the material characteristics, in particular its relative permittivity and loss tangent.

In this paper, the miniaturization of a $3 \mathrm{D}$ ceramic filter is proposed showing simultaneously small dimensions and low insertion loss. Two filter structures realizing an $8-\mathrm{MHz}$ passband at $2.5 \mathrm{GHz}$ with a two pole filtering function are designed and fabricated for comparison. The objective in terms of maximum footprint is $16 \mathrm{~mm} \times 16 \mathrm{~mm}$ and the insertion loss has to be as low as possible. The first filter is made of stacked parallelepipedic resonators while the second one is integrated in a single layer using capacitive posts for reducing the footprint of individual resonators.

\section{Filter MAdE OF StACKed CERAMIC RESONATORS}

\section{A. Parallelepipedic Resonator}

The dielectric resonator, described in Fig.1, is made of zirconia, a high-K $(\varepsilon r=33.3)$ high-Q $\left(\tan \delta=9.210^{-4}\right)$ ceramic material. The structure is metallized with a silver layer on its external faces. The resonator is dimensioned for working on its fundamental $\mathrm{TE}_{110}$ mode at $2.5 \mathrm{GHz}$. In this configuration, the lateral dimensions are found to be $14.4 \mathrm{~mm}$ while the height, which affects only the unloaded quality factor, is chosen to be $4 \mathrm{~mm}$.

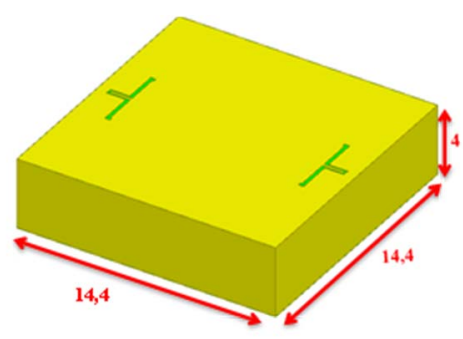

(a)

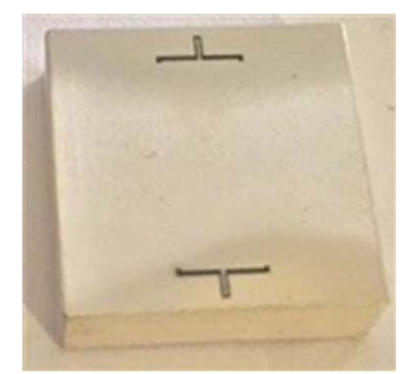

(b)

Fig. 1. Parallelepidic dielectric resonator made of zirconia. (a) CAD model, (b) prototype.

Coplanar ports are etched on top of the resonator, allowing exciting the structure. The structure has been fabricated and measured. The simulated (CST MWS ${ }^{\circledR}$ electromagnetic simulator) and measured scattering parameters, compared in Fig.2, allow extracting the unloaded quality factor, which is found to be 520 . 


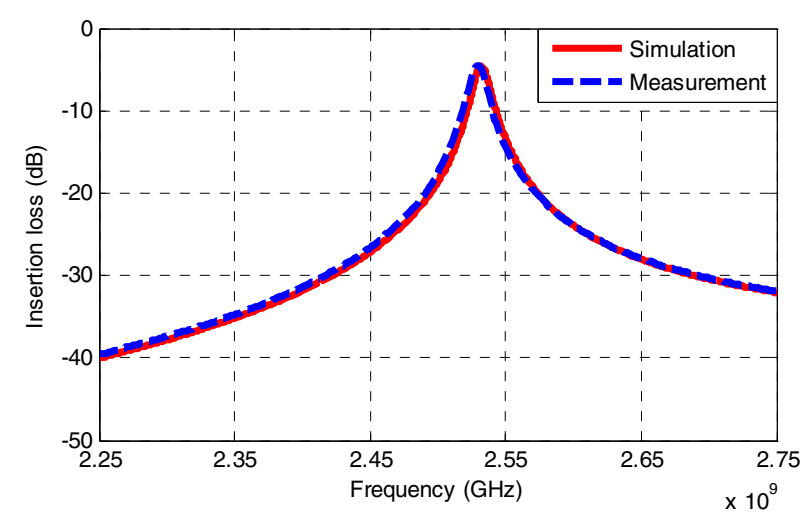

Fig. 2. Simulated and measured scattering parameters of the parallelepipedic dielectric resonator.

\section{B. Stacked Resonator Filter}

In order to fulfill the specification in terms of maximum footprint, the resonators have to be stacked. In order to couple stacked resonators, a rectangular aperture is etched in the metallic layers of each resonator as shown in Fig.3.

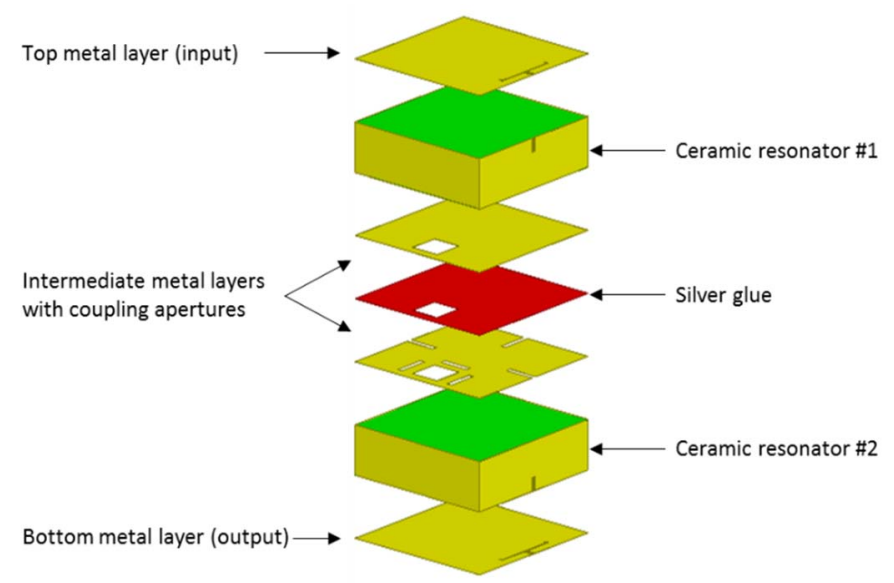

(a)

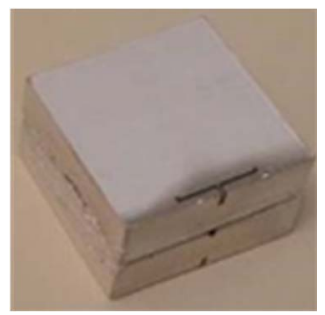

(b)

Fig. 3. Two-pole stacked dielectric resonator filter made of zirconia. (a) CAD model, (b) prototype.

The size of the rectangular aperture and the dimensions of the coplanar excitation pattern are optimized for realizing an 8$\mathrm{MHz}$ passband at $2.5 \mathrm{GHz}$, with a $20-\mathrm{dB}$ return loss. The overall dimensions are $14.4 \mathrm{~mm} \times 14.4 \mathrm{~mm} \times 8 \mathrm{~mm}\left(1659 \mathrm{~mm}^{3}\right)$, i.e. $\lambda_{0} / 8.3 \times \lambda_{0} / 8.3 \times \lambda_{0} / 15$ at $2.5 \mathrm{GHz}, \lambda_{0}$ being the free space wavelength.

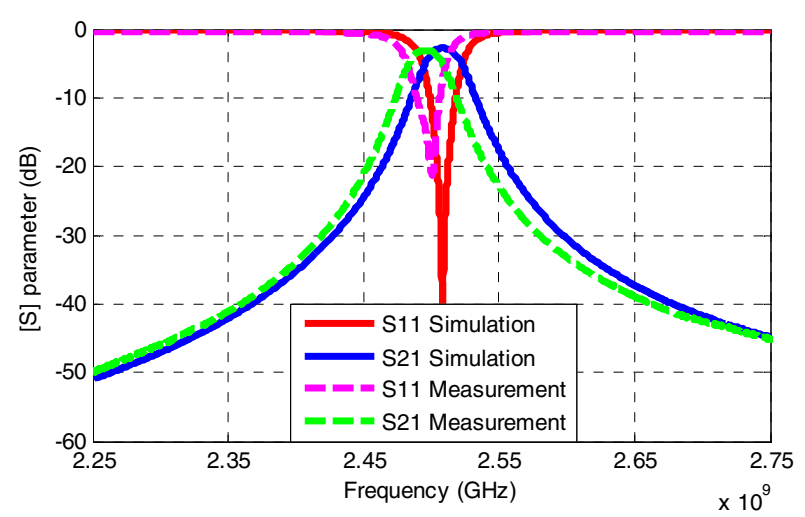

Fig. 4. Simulated and measured scattering parameters of the two-pole stacked dielectric resonator filter.

The filter has been fabricated and tested, and simulated and measured scattering parameters are compared in Fig.4, showing a good agreement. The insertion loss is found to be $2.8 \mathrm{~dB}$ in the simulation and $3.1 \mathrm{~dB}$ in the measurement. This slight discrepancy can be explained by a 2 degree misalignment between resonators during assembly process.

In order to reduce the height of the filter device, the structure is modified in order to implement the filter within a single layer.

\section{Filter MADE OF CERAMic Resonators on the SAME LAYER}

\section{A. Miniaturized Resonator}

The resonator is miniaturized by inserting a post in the middle of the resonator as shown in Fig.5. The length of the resonator is set to $16 \mathrm{~mm}$ and the width is set to $7.5 \mathrm{~mm}$ leaving $1 \mathrm{~mm}$ between two resonators for integration of a coupling element. The depth of the post is then optimized in order to tune the frequency at $2.5 \mathrm{GHz}$.

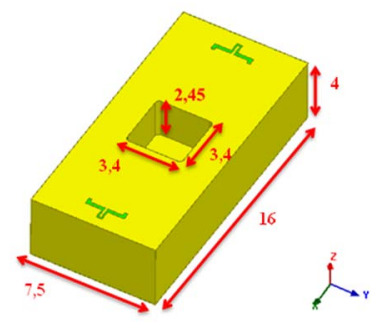

(a)

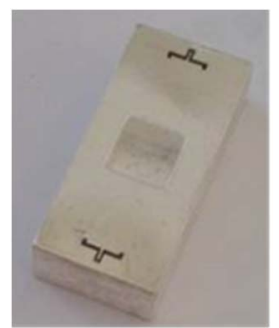

(b)

Fig. 5. Miniaturized dielectric resonator made of zirconia. (a) CAD model, (b) prototype. 


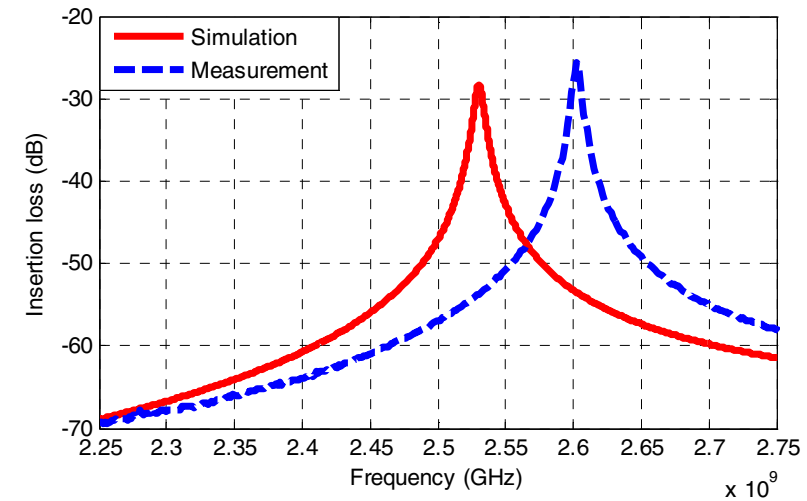

Fig. 6. Simulated and measured scattering parameters of the miniaturized dielectric resonator.

A prototype of the miniaturized filter has been fabricated and measured. The scattering parameters are compared in Fig.6. The resonant frequency is $60 \mathrm{MHz}$ higher in the measurement but the unloaded quality factor extracted from the measurement, which is about 390 , is in good agreement with the simulation.

\section{B. Miniaturized Resonator Filter}

The two-pole filter is designed as a monolithic structure made with two resonators as presented previously and connected with a lateral coupling aperture as described in Fig.7. The overall dimensions are $16 \mathrm{~mm} \times 16 \mathrm{~mm} \times 4 \mathrm{~mm}(1024$ $\mathrm{mm}^{3}$ ), i.e. $\lambda_{0} / 7.5 \times \lambda_{0} / 7.5 \times \lambda_{0} / 30$ at $2.5 \mathrm{GHz}$.

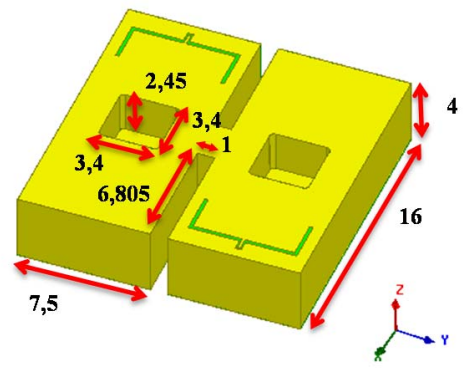

(a)

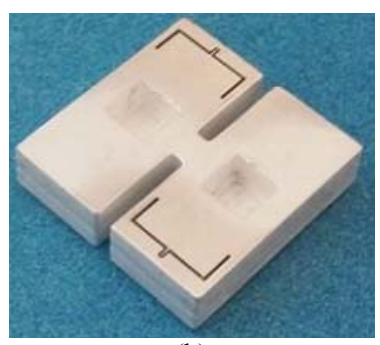

(b)

Fig. 7. Two-pole miniature monolithic dielectric resonator filter made of zirconia. (a) CAD model, (b) prototype.

The dimensions of the input/output coplanar patterns and of the coupling aperture are optimized in order to obtain an $8-\mathrm{MHz}$ passband at $2.5 \mathrm{GHz}$ with a $20-\mathrm{dB}$ return loss. A prototype has been fabricated and measured. The simulated and measured scattering parameters are compared in Fig.8.

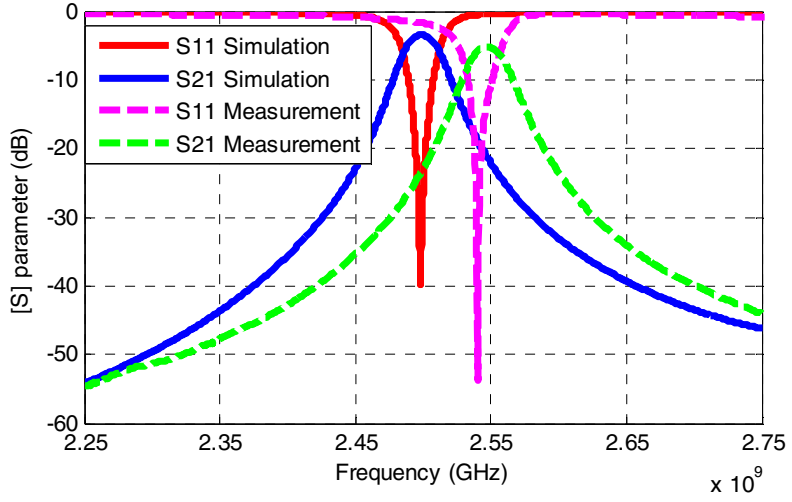

Fig. 8. Simulated and measured scattering parameters of the two-pole monolithic single-layer dielectric resonator filter.

The measured filter shows a $5-\mathrm{MHz}$ passband at $2.55 \mathrm{GHz}$ leading to a $5.2 \mathrm{~dB}$ insertion loss while the simulation predicts an insertion loss at $3.4 \mathrm{~dB}$ (for 8-MHz bandwidth).

The discrepancy is due to slightly different dimensions in the fabricated prototype as described in Fig.9a. The most sensitive parameters are the post dimensions. Using these measured dimensions in the CAD model, a good agreement is found with the measurement as shown in Fig.9b.

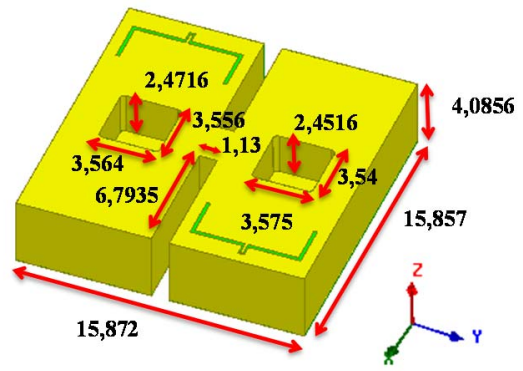

(a)

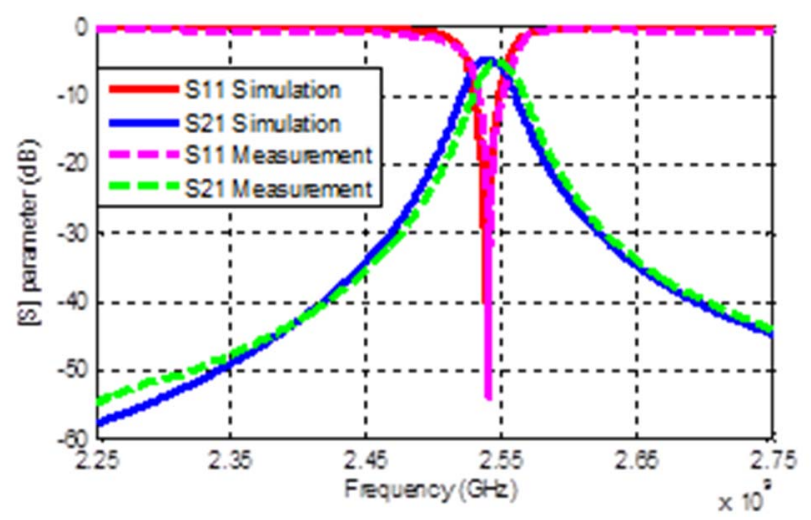

(b)

Fig. 9. (a) Dimensions measured on the fabricated prototype and simulation made with the $\mathrm{CAD}$ model taking into account measure dimensions. 
Table 1 - Simulated and measured characteristics of the stacked and monolithic two-pole filters

\begin{tabular}{|l|l|l|}
\hline Stacked filter & Simulation & Measurement \\
\hline Dimensions (mm, mm, mm) & $14.4 \times 14.4 \times 8$ \\
\hline Center frequency (GHz) & 2.5 & 2.49 \\
\hline Bandwidth (MHz) & 8 & 8 \\
\hline Insertion losses (dB) & 2.8 & 3.1 \\
\hline Monolithic filter & \multicolumn{2}{|l|}{} \\
\hline Dimensions (mm, mm, mm) & $16 \times 16 \times 4$ & 2.55 \\
\hline Center frequency (GHz) & 2.5 & 5 \\
\hline Bandwidth (MHz) & 8 & 5.2 \\
\hline Insertion losses (dB) & 3.4 & \multicolumn{2}{|l}{} \\
\hline
\end{tabular}

\section{CONCLUSION}

A high-Q miniature dielectric filter has been proposed. The structure are made of high permittivity and high $\mathrm{Q}$ ceramic material. Two configurations have been proposed for implementing a $16 \mathrm{~mm}$ x $16 \mathrm{~mm}$ two-pole filter exhibiting an $8-\mathrm{MHz}$ passband at $2.5 \mathrm{GHz}$. The first structure is made of two stacked parallelepipedic resonators, while the second is made of two resonators miniaturized thanks to capacitive posts for integrating the circuit in a single layer.

The structures have been designed using a CAD model, fabricated and measured. The main characteristics are summarized in Table I. The two configurations are found suitable for implementing compact high Q filters. The second configuration allows integrating the filter as a monolithic circuit but the structure seems to have some limitations related to the miniaturization of the resonator: sensitivity to the dimensions of the post, substantially higher insertion losses.

\section{REFERENCES}

[1] J. Hong, M. Lancaster, "Aperture-coupled microstrip open-loop resonators and their applications to the design of novel microstrip bandpass filters," IEEE Trans. Microw. Theory Tech., vol. 47, no 9, pp. 1848-1855, Sep. 1999.

[2] M. Gil, J. Bonache, J. Garcia-Garcia, J. Martel, F. Martin, "Composite right/left-handed metamaterial transmission lines based on complementary split-rings resonators and their applications to very wideband and compact filter design," IEEE Trans. Microw. Theory Tech., vol. 55, no 6, pp. 1296-1303, Jun. 2007.

[3] S. Luo, L. Zhu, "A novel dual-mode dual-band bandpass filter based on a single ring resonator," IEEE Microw. Wirel. Compon. Lett., vol. 19, no 8, p. 497-499, Aug. 2009.

[4] C.-Y. Hsu, C.-Y. Chen, H.-R. Chuang, "A miniaturized dual-band bandpass filter using embedded resonators," IEEE Microw. Wirel. Compon. Lett., vol. 21, no 12, p. 658-660, Dec. 2011.

[5] A. Gorur and C. Karpuz, "Miniature dual-mode microstrip filters," IEEE Microw. Wirel. Compon. Lett., vol. 17, no 1, p. 37-39, Jan. 2007.

[6] R. Weigel, et al., "Microwave acoustic materials, devices, and applications," IEEE Trans. Microw. Theory Tech., vol. 50, no 3, pp. 738 -749, Mar. 2002.

[7] L. Catherinot, et al., "A general procedure for the design of bulk acoustic wave filters," Int. J. of RF and Microw. Computer-Aided Eng., vol. 21, no. 5, pp 458-465, Sep. 2011.

[8] X.P. Chen, K. Wu, "Substrate integrated waveguide cross-coupled filter with negative coupling structure," IEEE Trans. Microw. Theory Tech., vol. 56, no 1, pp. 142-149, Jan. 2008.

[9] Y.D. Dong, T. Yang, T. Itoh, "Substrate integrated waveguide loaded by complementary split-ring resonators and its applications to miniaturized waveguide filters," IEEE Trans. Microw. Theory Tech., vol. 57, no 9, pp. 2211-2223, Sep. 2009.
[10] C. Menudier, et al., "Innovative materials and fabrication process to develop new RF components and concepts," in 11th European Conf. on Antennas and Propag. (EUCAP), Paris, France, Mar. 2017 